\title{
Hot water injection in relation to $1982-84$ microseismic events at Campi Flegrei Caldera by thermo-hydro-mechanical simulation
}

\author{
Waheed Gbenga Akande ${ }^{1,2, *}$, Quan Gan ${ }^{1}$, Luca De Siena ${ }^{1,3}$ and David G. Cornwell ${ }^{1}$ \\ ${ }^{1}$ University of Aberdeen, Geology and Petroleum Geology Department, AB24 3UE, King's College Campus, United Kingdom \\ ${ }^{2}$ Federal University of Technology, Geology Department, P.M.B. 65, Bosso Campus, Minna, Nigeria \\ ${ }^{3}$ Johannes Gutenberg University, Institute of Geosciences, 55128 Mainz, Germany
}

\begin{abstract}
The repeated deformations and seismic unrests at Campi Flegrei caldera (southern Italy) have been identified due to a fluid injection source in volcano active area. We investigated the role of hot water injection in the seismic unrests of 1982-1984 with a view to gaining insights into the caldera's dynamics, by applying coupled TOUGHREACT-FLAC ${ }^{3 \mathrm{D}}$ simulator to our computational domain of $10 \times 1 \times 3 \mathrm{~km}$ with a single-phase steam isothermal (HM) and non-isothermal (THM) simulations comparison. The results indicated that the overlying caprock blocks the uprising hot water injection, leading to the building up of pore pressure and shear stress underneath over time. This process substantially modified the ambient stress regime, strained the caprock, led to microfractures formation which enhanced hydraulic properties of the system, and ultimately provided conductive migration pathways for hot fluids to pressurize the shallow overlying fault. The prolonged shear stress accumulation period culminated in shear fracturing, dilation and fault slips, whose displacements are in order of millimetres to few centimetres. The moment magnitudes of seismicity generated were generally in order of 3.0. The seismic slips occurred at $\sim 7$ and $\sim 6$ days under HM and THM cases, respectively - giving a time delay in the order of $\sim 1$ day in the isothermal case. A comparison of our results for isothermal and non-isothermal cases suggests that seismic slips occurred generally earlier at higher fluid injection rates and under non-isothermal conditions. Further examinations of thermal effects showed that fault slips generally occur earlier at higher injection temperatures and/or at high host rock/fluid injection temperature contrasts. At very low permeabilities (e.g., $10^{-19} \mathrm{~m}^{2}$ ), fault slips were delayed and the required time for shear stress accumulation to trigger slips is about 8 days. It is concluded that an interplay among variables such as injection rates, fluid injection temperatures and caprock permeabilities determines the timing of a seismic fault slip and associated seismicity at the caldera.
\end{abstract}

\section{Introduction}

Campi Flegrei caldera ( $\mathrm{CFc}$, southern Italy) is one of the world's best known calderas situated on an active volcano. Fluid injection and magmatic degassing have been invoked to explain the repeated ground deformations and seismic unrests at the caldera (e.g., [14]). Since water and carbon dioxide are the major fluid components of a magmatic system, several numerical simulation studies involving these fluids, either as a single phase (or multiphase) or single component (or a mixture), have been carried out at the $\mathrm{CFc}$ to understand ground deformation and associated seismicity (e.g., [12], [4-8]).

Careful reviews of the literature reveal some drawbacks in the existing studies related to homogeneous assumptions of properties for geological layers in model parameterization, for example, using uniform permeability in the model, which instead can significantly vary in such a structurally complex volcano. This has, however, been partly addressed in studies by Troiano et al. [6], Coco et al. [8] and Chiodini et al. [4]. Besides, the roles of the "caprock", which has been consistently deduced from rock physics characterization (e.g., [9]) and seismic tomographic studies (e.g., [10-11]), has been completely neglected in the available simulation studies of ground deformation and seismic unrests at the CFc. To keep the numerical problem simpler in the current study, we adopted the approach of Taron et al. [12] to model fluid flow from a single phase hot water injection under both isothermal and non-isothermal simulation conditions to explore the roles of hydro-mechanical (HM) and thermo-hydromechanical (THM) effects in relation to seismic fault slip and accompanied seismicity. We introduced caprock properties into our numerical model for the caldera and tested various values of caprock permeability to understand its roles in modulating an eruption at the caldera. We describe our numerical model and modelling methodology in the next section, and present the results and discussion afterwards. Our findings demonstrate that combined thermal and hydromechanical effects drive seismic unrests at the $\mathrm{CFc}$.

$\overline{\text { * Corresponding author: waheed.akande } @ \text { abdn.ac.uk }}$ 


\section{Methodology}

\subsection{Description of Numerical Model for the CFc}

The basics of the methodology adopted in this study have been comprehensively described by Taron et al. [12]. It involves coupling of mechanical deformation simulator (Fast Langrangian Analysis of Continua in three dimensions, FLAC $^{3 \mathrm{D}}$ ) with a fluid flow and heat flow simulator (Transport Of Unsaturated Groundwater and Heat, TOUGHREACT), and Interpolation Module where the activities of the simulators are coordinated, Fig. 1.

A three-dimensional model of $10 \mathrm{~km} \times 1 \mathrm{~km} \times 3$ $\mathrm{km}$ dimensions (Fig. 2) was built for the $\mathrm{CFc}$, and its parameterization is based on the data obtained from drilling and productivity tests by the AGIP Company ([13]), and deductions from rock physics characterization ([9]) and seismic tomograhphic studies ([10-11]). The basal aquifer is defined around 2500$3000 \mathrm{~m}$ and overlain by caprock of approximately $500 \mathrm{~m}$ thickness ([10]) at a depth of about 2000-2500 m, and the middle and upper reservoirs are at depths of 1800 $2000 \mathrm{~m}$ and 500-1000 m, respectively (Fig. 2).

An explicit fault architecture was developed by including in the model a plane of structural weakness representing the fault with a dip of $60^{\circ}$, whose width was modelled as $10 \mathrm{~m}$ ([14]), and the fault crossed the upper discretized layers and terminated on top of the caprock (Fig. 2). The fracture systems at the $\mathrm{CFc}$ are predominantly of normal kinematics and have steep dip angles which are often greater than $60^{\circ}$ ([14-15]). A $60^{\circ}$ dip fault angle is most preferable in this work, compared to other tested dip angles $\left(70^{\circ}\right.$ and $\left.80^{\circ}\right)$ because it gives more robust computational results (Fig. 3). The fault zone was modelled as a single homogeneous entity, without being partitioned into a fault core and damage zone, as the variations of properties across these zones were not the major focus of the present study. The fault was represented as solid elements with ubiquitous joints oriented as weak planes, implementing the recommendations of the approach used by Cappa and Rutqvist [16] and Gan and Elsworth [17]. Uniform fracture spacing distributions of $10 \mathrm{~m}$ and $0.1 \mathrm{~m}$ were chosen for the host rock and fault zone, respectively, owing to the caldera-wide scale of the model and using outcrop analogue observations ([15]). A vertical injection source was designed and positioned at a depth of $3 \mathrm{~km}$ at the centre of the model, representing injection of hot water from a deeper feeding system (e.g., a deformation source at $4 \mathrm{~km}$; [10]).

\subsection{Model Settings and Properties}

The initial principal stresses in three directions: $(x, y$, and $z$ ) are $45.5 \mathrm{MPa}, 64.0 \mathrm{MPa}$ and $66.0 \mathrm{MPa}$ with their corresponding stress gradients of $15.0 \mathrm{MPa} / \mathrm{km}, 20.67$ $\mathrm{Ma} / \mathrm{km}$ and $21.33 \mathrm{MPa} / \mathrm{km}$, respectively. The pore pressure gradient is assumed as $10.0 \mathrm{MPa} / \mathrm{km}([18])$. The model is mechanically stable and at equilibrium under these simulation conditions.

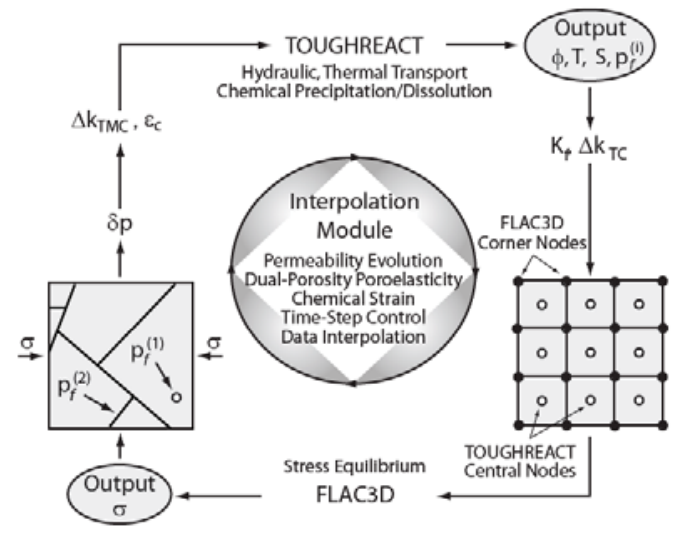

Figure 1. FLAC ${ }^{3 \mathrm{D}}$ - TOUGHREACT coupling model (Taron et al. [12]).

(a)

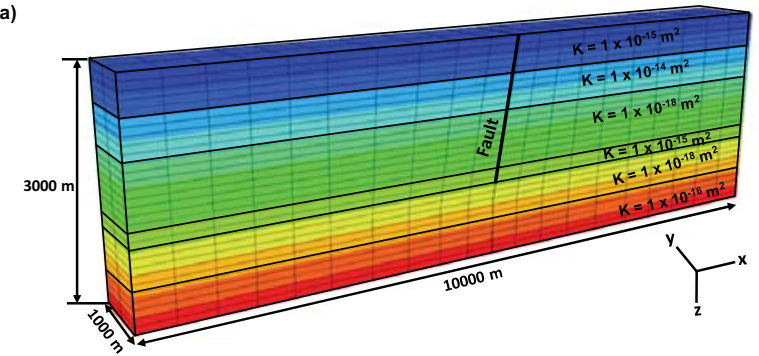

(b)

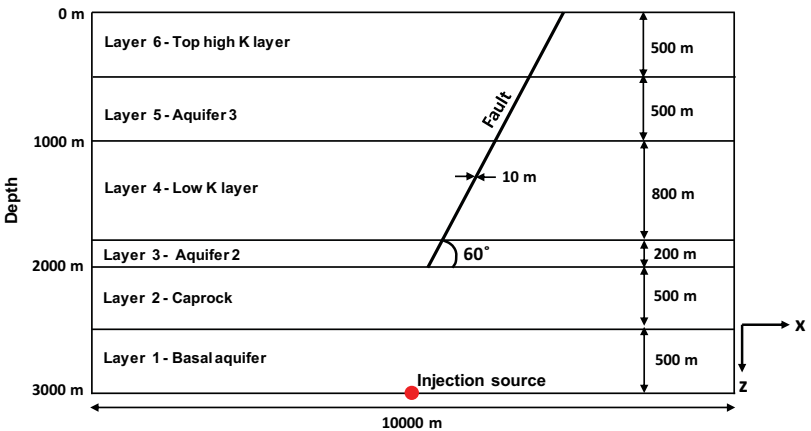

Figure 2. Model geometry for the study: (a) 3-D mesh construction from FLAC $^{3 \mathrm{D}}$ showing discretization of the model into six layers and the fault dipping at $60^{\circ}$, (b) 2-D sketch of (a) showing discretized layers, the fault, and location of the injection point in the simulation. Permeability $\left(\mathrm{K}, \mathrm{m}^{2}\right)$ values are from AGIP [13].

The model was then populated with material properties such as elastic moduli (e.g., shear modulus and bulk modulus) and Poisson's ratio; hydraulic properties (e.g., permeability) as shown in Table 1; and assigned mechanical properties (cohesion, tensile strength, friction angle and dilation angle) as shown in Table 2.

The fault was modelled as a cohesionless (cohesion, $\mathrm{c}=0$ ) structural element and assigned a lower internal friction angle than the matrix. While the matrix was assigned the Mohr-Coulomb model, the fault was modelled with the strain-hardening/softening ubiquitous (subi) joint constitutive model type of FLAC ${ }^{3 \mathrm{D}}$. 
Table 1. Material properties used for the simulation.

\begin{tabular}{|c|c|c|c|}
\hline Parameters & $\begin{array}{c}\text { Symbols } \\
\text { (Units) }\end{array}$ & Values & References \\
\hline Matrix porosity & $\phi_{m}(\%)$ & 20 & [2] \\
\hline Fault porosity & $\phi_{f}(\%)$ & 30 & \\
\hline $\begin{array}{c}\text { Matrix } \\
\text { permeability }\end{array}$ & $k_{m}\left(\mathrm{~m}^{2}\right)$ & $\begin{array}{l}1.0 \times 10^{-18}- \\
1.0 \times 10^{-14}\end{array}$ & [13] \\
\hline $\begin{array}{c}\text { Fault } \\
\text { permeability }\end{array}$ & $k_{f}\left(\mathrm{~m}^{2}\right)$ & $1.0 \times 10^{-13}$ & {$[9,19]$} \\
\hline Density & $\rho\left(\mathrm{kg} / \mathrm{m}^{3}\right)$ & $1800-2500$ & [13] \\
\hline \multicolumn{4}{|c|}{ Caprock } \\
\hline Matrix porosity & $\phi(\%)$ & $9-20\left(10^{*}\right)$ & \\
\hline $\begin{array}{c}\text { Matrix } \\
\text { permeability }\end{array}$ & $k(\mu \mathrm{D})$ & $\begin{array}{c}2-30(1.0 \times \\
\left.10^{-18^{*}}\right)\end{array}$ & [9] \\
\hline Bulk Modulus & $K(\mathrm{GPa})$ & 15 & \\
\hline Shear Modulus & $G(\mathrm{GPa})$ & 13 & \\
\hline Poisson's ratio & $v(-)$ & 0.16 & \\
\hline
\end{tabular}

${ }^{*}$ Permeability of caprock (in $\mathrm{m}^{2}$ ) used in this study.

Table 2. Mechanical and thermal properties used for the simulation.

\begin{tabular}{c|ccc}
\hline Parameters & $\begin{array}{l}\text { Symbols } \\
(\text { Units })\end{array}$ & Values & References \\
\hline Matrix friction angle & $\varphi_{m}\left({ }^{\circ}\right)$ & 50 & {$[20]$} \\
Fault friction angle & $\varphi_{f}\left({ }^{\circ}\right)$ & 30 & {$[21]$} \\
Matrix cohesion & $c_{m}(\mathrm{MPa})$ & 5.0 & {$[22]$} \\
Fault cohesion & $c_{f}(\mathrm{MPa})$ & 0 & {$[23]$} \\
Matrix dilation & $\Psi_{m}\left({ }^{\circ}\right)$ & 3 & {$[20]$} \\
Fault dilation & $\Psi_{f}\left({ }^{\circ}\right)$ & 0 & {$[22]$} \\
Matrix tensile & $t_{m}(\mathrm{MPa})$ & $2.57^{* *}$ & {$[22]$} \\
strength & & & \\
Fault tensile strength & $t_{f}(\mathrm{MPa})$ & 0 & {$[23]$} \\
Matrix Bulk Modulus & $K_{m}(\mathrm{GPa})$ & $5.26^{* *}$ & {$[24]$} \\
Fault Bulk Modulus & $K_{f}(\mathrm{GPa})$ & 10.0 & {$[16]$} \\
Matrix Shear & $G_{m}(\mathrm{GPa})$ & $3.1^{* *}$ & {$[24]$} \\
Modulus & & & \\
Fault Shear Modulus & $G_{f}(\mathrm{GPa})$ & 6.0 & {$[16]$} \\
Poisson ratio & $v(-)$ & $0.30^{* *}$ & {$[24]$} \\
Coefficient of & $A(\mathrm{~J} / \mathrm{kgK})$ & $40.0 \times$ & {$[25]$} \\
Thermal Expansion & & $10^{-6}$ & \\
\hline ** Values used for the matrix except for the caprock (See Table
\end{tabular}
$1)$.

\subsection{Simulation Scenarios: HM and THM}

The simulation conditions such as injection rates, injection temperatures and the fault's dip angles used for this study are summarized in Table 3. Of these conditions, a dip angle of $60^{\circ}$ and injection rate of 150 $\mathrm{kg} / \mathrm{s}$ in Case A produced optimum results (yielding fault slip at a reduced time) in the isothermal mode (Fig. 3), and this allowed the evaluation of the hydro-mechanical effect of hot-water injection. While the temperature of the geological layers was held constant, simulation scenarios using varied injection temperatures of 200 , 250,300 , and $350^{\circ} \mathrm{C}$ were run under non-isothermal simulation conditions to assess thermal effects (Table 3, Case B). As highlighted in Table 1, the caprock permeability used in this study is $10^{-18} \mathrm{~m}^{2}$ ([9]); however, we examined the influence of caprock permeabilities in the range of $10^{-17}-10^{-19} \mathrm{~m}^{2}$ (Table 3, Case C).
However, only the results for these conditions, and those for effects of caprock permeabilities under THM conditions (because of more enhanced influence), are more emphasized in this study because of limited space.

Seismic fault slips in natural earthquakes are often discontinuous owing to a slip weakening process. Thus, we developed a friction table and used it to model fault slip and seismicity in line with the friction laws of natural earthquakes (e.g., [26]).

Table 3. Simulation conditions used for different cases considered in the study under HM and THM conditions.

\begin{tabular}{c|cccc}
\hline Case & $\begin{array}{c}\text { Dip } \\
\text { angle }\left({ }^{\circ}\right)\end{array}$ & $\begin{array}{c}\text { Injection } \\
\text { rate } \\
(\mathrm{kg} / \mathrm{s})\end{array}$ & $\begin{array}{c}\text { Injection } \\
\text { temperature } \\
\left({ }^{\circ} \mathbf{C}\right)\end{array}$ & $\begin{array}{c}\text { Caprock } \\
\text { Permeability } \\
\left(\mathrm{m}^{2}\right)\end{array}$ \\
\hline & & $\mathbf{3 7 . 5}$ & 350 & $10^{-18}$ \\
$\mathbf{A}$ & $60,70,80$ & $\mathbf{5 0 . 0}$ & 350 & $10^{-18}$ \\
& & $\mathbf{1 0 0 . 0}$ & 350 & $10^{-18}$ \\
& & $\mathbf{1 5 0 . 0}$ & 350 & $10^{-18}$ \\
\hline & 60 & 150.0 & $\mathbf{2 0 0}$ & $10^{-18}$ \\
$\mathbf{B}$ & & 150.0 & $\mathbf{2 5 0}$ & $10^{-18}$ \\
& & 150.0 & $\mathbf{3 0 0}$ & $10^{-18}$ \\
& & 150.0 & $\mathbf{3 5 0}$ & $10^{-18}$ \\
\hline & 60 & 150.0 & 350 & $\mathbf{1 0}^{-17}$ \\
$\mathbf{C}$ & & 150.0 & 350 & $\mathbf{1 0}^{-18}$ \\
& & 150.0 & 350 & $\mathbf{1 0}^{-19}$ \\
\hline
\end{tabular}

(a)

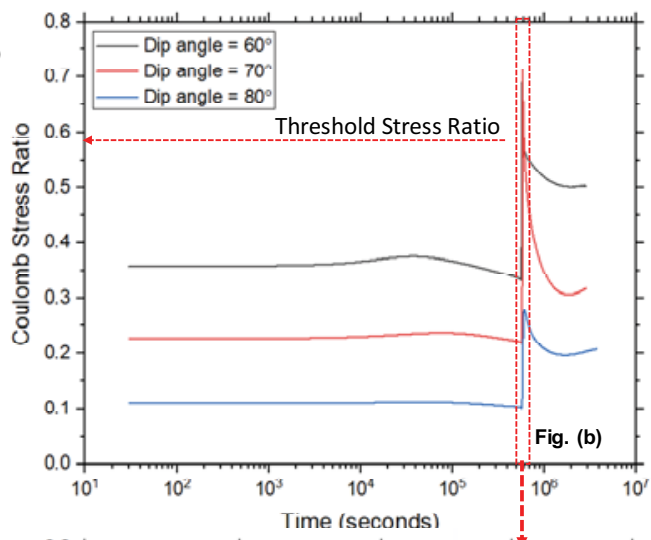

(b)

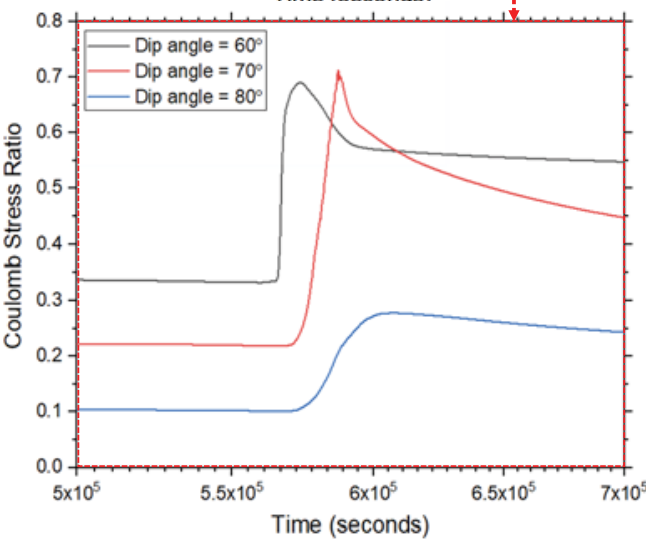

Figure 3. (a) Comparison of Coulomb stress ratio evolution for fault dip angles of $60^{\circ}, 70^{\circ}$ and $80^{\circ}$ at $150 \mathrm{~kg} / \mathrm{s}$ injection rate, and (b) large view of (a) showing the time window of $5.0 \times 10^{5}$ to $7.0 \times 10^{5}$ seconds - $60^{\circ}$-dip angle has the highest shear fracturing magnitude and most reduced timing of fault slip. 


\section{Results}

\subsection{Analyses of Results and Computations}

Results obtained from various simulation scenarios were analysed, and the instability of the fault was assessed by quantifying the evolution of stress state. The shear stress $(\tau)$, normal stress $\left(\sigma_{n}\right)$, effective normal stress $\left(\sigma_{n}^{\prime}\right)$, and Coulomb stress ratio $(\eta)$ were obtained using the following equations [16]:

$$
\begin{aligned}
& \sigma_{n}=\frac{\sigma_{1}+\sigma_{3}}{2}-\frac{\sigma_{1}-\sigma_{3}}{2} \cos 2 \theta-\tau_{x Z} \sin 2 \theta \\
& \sigma_{n}^{\prime}=\sigma_{n}-P \\
& \tau=\frac{\sigma_{1}-\sigma_{3}}{2} \sin 2 \theta-\tau_{x z} \cos 2 \theta \\
& \text { Coulomb stress ratio, } \boldsymbol{\eta}=\frac{\tau}{\sigma_{n}^{r}}
\end{aligned}
$$

In these equations, $\sigma_{3}$ is the minimum principal stress, $\sigma_{1}$ is the maximum principal stress, $\tau_{x z}$ is the $x-z$ plane shear stress component, $\theta$ is the direction of the maximum principal stress from the fault plane (Fig. 4a), and $P$ is the pore fluid pressure. The expression in Eqn. (2) is often referred to as the Effective Stress Law credited to Terzaghi [27].

When combining the effective stress law with the Coulomb failure criterion ([28]), the conditions for fault slip to occur at a fault with a specified orientation can be written as ([16]):

$$
\tau=c+\mu_{s} \sigma_{n}^{\prime}
$$

where $\tau$ is the threshold shear stress for fault slip, $c$ is the material cohesion strength, and $\mu_{s}$ is the static coefficient of friction whose magnitude is defined as:

$\mu_{s}=\tan \varphi$

where $\varphi$ is the internal friction angle.

According to Baisch et al. [29], for normal and shear stresses resolved along a fault plane, fault slip occurs when the ratio of shear stress to effective normal stress (Eqn. 4) exceeds the frictional coefficient of the fault plane (i.e., $\eta>\mu$ ). This ratio is called the Coulomb stress ratio ([17]), and it is also referred to as the "slip tendency" or "ambient stress ratio" ([16]). The friction angle used in this study was $30^{\circ}$ ([21]), corresponding to a coefficient of internal friction of 0.577 . Thus, seismic fault slip was expected when $\eta \approx 0.58$.

\subsection{Results of HM and THM Simulations}

The results for both isothermal and non-isothermal simulations show that pore pressure took a reasonable length of time in the order of days ( 6 days) to build up beneath the caprock before it could trigger seismic fault slips (Figs. 5-7). Hot water injection from depth produced enhanced pore pressure, which significantly modified the ambient stress regime while propagating through the basal reservoir (injection formation), and the

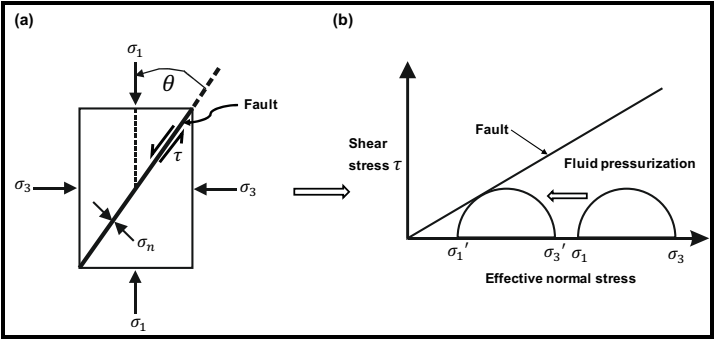

Figure 4. Fault plane stress analysis: (a) resolution of normal stresses along a fault plane with a given orientation from the remote principal stresses ([16]), (b) slip failure mechanism by fluid pressurization ([17]).

hydraulic and mechanical properties of the caprock allowed it to withstand the rigour of shear stress accumulation at the caprock/basal aquifer interface. Figure 5 illustrates that caprock permeability influences the pore pressure build-up and distribution, and perhaps controls the timing of fault slips. This figure indicates that shear fracturing occurred earlier at higher caprock permeability, while there was a delay in fault slip timing at low caprock permeabilities (e.g., $10^{-19} \mathrm{~m}^{2}$ ). Figure 6 compares the results of isothermal and non-isothermal simulations at injection rate of $150 \mathrm{~kg} / \mathrm{s}$, suggesting that there was a thermal delay of $\sim 1$ day before the onset of fault slip under isothermal (HM) condition. Figure 7 reveals that seismic slips generally occur at higher fluid injection temperatures as expected, but the slip timing is controlled by the contrasts between the host rock temperature (assumed as $100^{\circ} \mathrm{C}$ here for a relatively stable geological formation of geothermal gradient of $\sim 30^{\circ} \mathrm{C} / \mathrm{km}$ at $\mathrm{z}=3.0 \mathrm{~km}$ ) and fluid injection temperature.

\section{Discussion of Results}

\subsection{Roles of Fluid Injection and Caprock in Seismic Fault Slips}

Fluid injections including water injection at high pressure into injection formation can trigger seismicity in critically stressed Earth's crust or along an optimally oriented fault (e.g., [30]). Also, at an active volcano such as the $\mathrm{CFc}$, previous studies have established a link among the ground deformation, subsidence and seismicity (e.g., [8, 31]). Fluid injection and magmatic degassing from depth ([3-4]) causes pore pressure front to expand in the injection formation. This study showed that pore pressure build-up is associated with shear accumulation beneath the caprock and accompanied by compressional and extensional regimes at lower and upper portions of the caprock, respectively (Fig. 5). The timing of shear strain sustained by the caprock and onset of shear fracturing is a function of its permeability and mechanical strength [9]. However, when the threshold point is exceeded and the caprock could no longer withstand the strain effect, microfractures began to develop, then propagate and coalesce to enhance the permeability of the caprock. The beached caprock then 


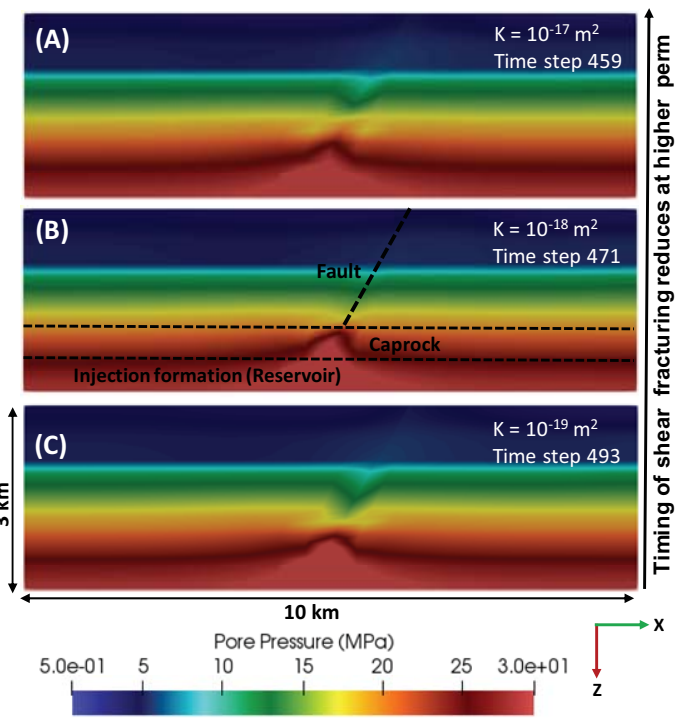

Figure 5. Pore pressure distributions at the end of the hot water injection for THM simulations at the indicated caprock permeabilities $\left(\mathrm{K}, \mathrm{m}^{2}\right)$.

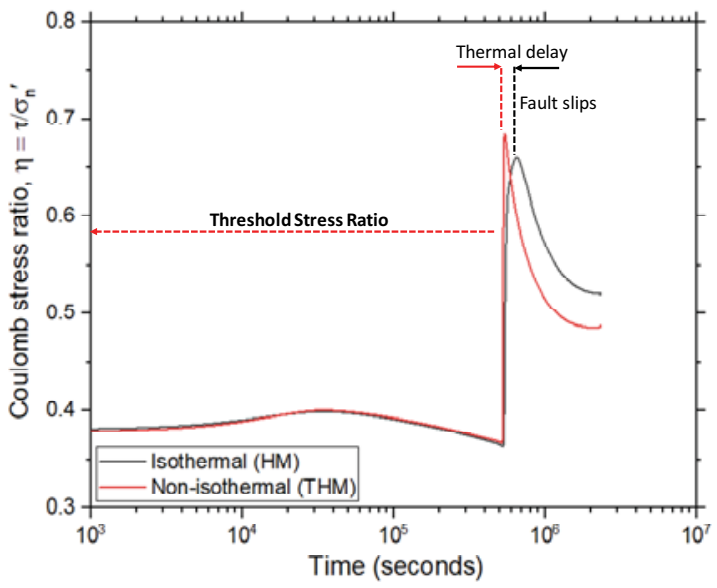

Figure 6. The evolution of fault Coulomb stress ratio: Comparison of simulation results of HM and THM effects.

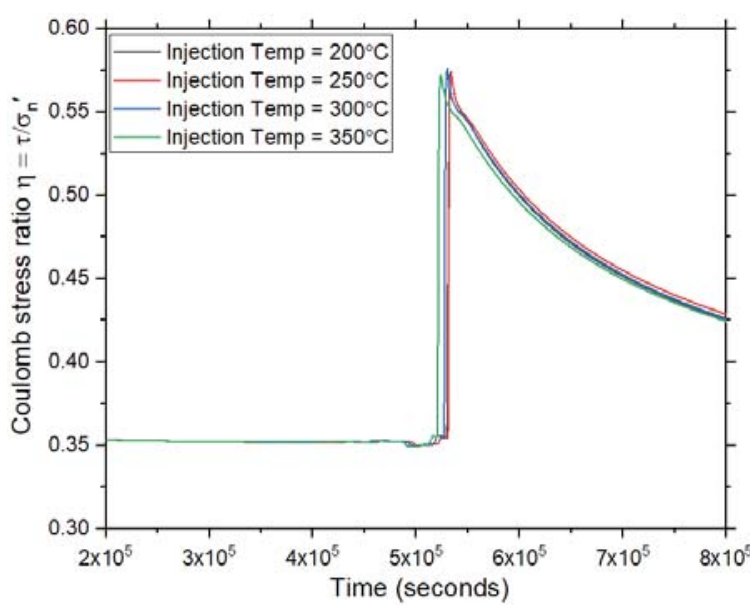

Figure 7. The evolution of fault Coulomb stress: Comparison of results of THM effects at various indicated injection temperatures. provided conductive migration pathways for the rising hot water to pressurize the shallower overlying fault. This brought instability to the fault as its frictional strength diminished, and it then failed. The shear stress accumulation continued until after $\sim 6$ days of hot water injection before the fault slip occurred (Fig. 6). Such long periods of stress accumulation are often observed in advance of volcanic eruptions or earthquakes to the point where fault criticality is reached and the shear stress cannot be sustained any longer, and thus rocks tend to fracture and earthquakes or eruptions occur (e.g., [32]).

Our results also indicate that seismic fault slips occur at higher fluid injection rates (often with reduced fault slip timing), and slips were observed at an injection rate around $100 \mathrm{~kg} / \mathrm{s}$ (Fig. 8), which is in agreement with most existing studies carried out under similar conditions such as an injection temperature of $350^{\circ} \mathrm{C}$ in the area (e.g., [1-6, 8]). The works of Todesco et al. [1-2] in particular arbitrarily increased the injection rate to simulate the HM and THM effects. The exception is the study by Afanasyev et al. [7], who introduced MUFITS simulator that is capable of modelling fluids in supercritical state.

It is observed in Fig. 5 that the pore pressure distributions and shear fracturing are dependent on caprock permeabilities. It takes a longer period (e.g., $\sim 8$ days) for pore pressure to build up before shear fracturing could occur in the more impervious caprock (very low-permeability sealing formation, e.g., Fig. 5C). According to Zhou et al. [33], this is not difficult to explain because the pore pressure front can propagate more easily into the caprock or perhaps even into the overlying aquifer when the seal is more permeable.

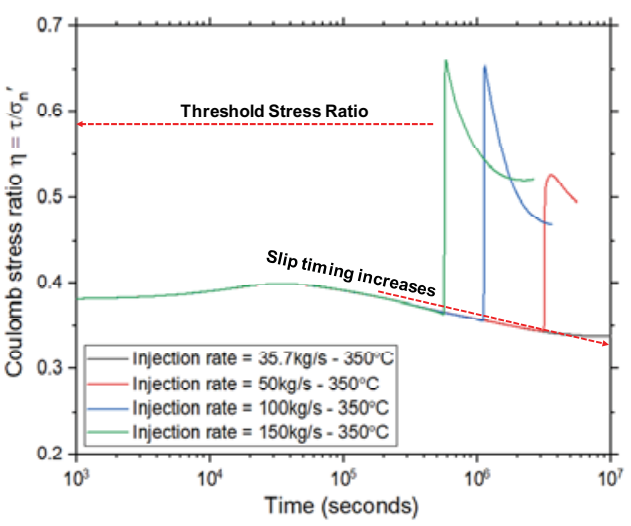

Figure 8: Comparison of fault Coulomb stress ratio evolution for different injection rates under HM condition. Results for the THM case show that respective fault slips occur earlier in time.

\subsection{HM and THM Effects Comparison}

The results of this study show that fault slips occurred earlier under the influence of thermal effects. Figure 6 indicates that the THM effect triggers seismicity earlier, and there is a time delay of $\sim 1$ day before the onset of seismic fault slip, for example in the HM case. This is perhaps due to thermal pressurization of the injection formation (basal aquifer) and thermally-induced stress accompanied by hot water injection. It was also observed 
that as the injection temperature or thermal contrasts increased, the time for corresponding fault slips to occur was reduced (Fig. 7). Thus, we infer that the temperature differential between the host rock and the injection fluid may be critical in triggering fault slips by the THM effect, and this may control spatial distributions of seismicity with depths. Thus, HM and THM effects may complement each other in controlling seismicity across depths in the subsurface of the CFc.

Fault slip analyses revealed that fault displacements are generally in order of millimetres to occasionally few centimetres. The magnitudes of seismicity computed using an empirical equation of Kanamori and Brodsky [34] are generally in order of 3.0 under both isothermal and non-isothermal conditions, indicating low- to moderate-magnitude seismicity. Thus, modelled THM effects explain the observed microseismicity at the CFc.

\section{Conclusions}

This study has shown the critical role caprock plays in modulating an eruption in an active volcano such as Campi Flegrei. Our results indicate that both hydromechanical and thermal effects are responsible for the seismic slips, and by extension microseismicity observed at this caldera. The thermal effect prompts seismic slip earlier than when only hydro-mechanical effect is involved. Thus, injection rates, fluid injection temperatures and caprock permeabilities are critical factors that determine the timing (and magnitude) of a seismic fault slip at the CFc. These observations may also be valid for other similar active volcanoes.

We acknowledge the financial support of the Petroleum Technology Development Fund (PTDF) Nigeria for this research.

\section{References}

1. M. Todesco, G. Chiodini, G. Macedonio, Monitoring and modelling hydrothermal fluid emission at La Solfatara (Phlegrean Fields, Italy); an interdisciplinary approach to the study of diffuse degassing, J. Volcanol. Geotherm. Res. 125, 57-79 (2003).

2. M. Todesco, J. Rutqvist, G. Chiodini, K. Pruess, C.M. Oldenburg, Modeling of recent volcanic episodes at Phlegrean Fields (Italy): geochemical variations and ground deformation, Geothermics 33, 531-547 (2004).

3. M.G. Chiodini, M. Todesco, S. Caliro, C. Del Gaudio, G. Macedonio, M. Russo, Magma degassing as a trigger of bradyseismic events; the case of Phlegrean Fields (Italy), Geophys. Res. Lett. 30, 1434 (2003).

4. M.G. Chiodini, S. Caliro, P. De Martino, R. Avino, F. Gherardi, Early signals of new volcanic unrest at Campi Flegrei caldera? Insights from geochemical data and physical simulations, Geology 40, 943-946 (2012).
5. A.P. Rinaldi, M. Todesco, M. Bonafede, Hydrothermal instability and ground displacement at the Campi Flegrei caldera, Phy. of the Earth and Planetary Interiors 178, 155-161 (2010).

6. A. Troiano, M.G. Di Giuseppe, Z. Petrillo, C. Troise, G. De Natale, Ground deformation at calderas driven by fluid injection: modelling unrest episodes at Campi Flegrei (Italy), Geophys. J. Int. 187, 833-847 (2011).

7. A. Afanasyev, A. Costa, G. Chiodini, Investigation of hydrothermal activity at Campi Flegrei caldera using 3D numerical simulations: extension to high temperature processes, J. Volcanol. Geotherm. Res. 299, 68-77 (2015).

8. A. Coco, G. Currenti, J. Gottsmann, G. Russo, C. Del Negro, Numerical models for ground deformation and gravity changes during volcanic unrest: simulating the hydrothermal system dynamics of a restless caldera, Jour. of Math. Ind. 6(6), 1-20 (2016).

9. T. Vanorio, W. Kanitpanyacharoen, Rock physics of fibrous rocks akin to Roman concrete explains uplifts at Campi Flegrei Caldera, Science 349 (6248), 617-621 (2015).

10. L. De Siena, G. Chiodini, G., Vilardo, E. Del Pezzo, M. Castellano, S. Colombelli, N. Tisato, G. Ventura, Source and dynamics of a volcanic caldera unrest: Campi Flegrei, 1983-84, Scientific Reports 7 (8099), 1-13 (2017).

11. W. G. Akande, L. De Siena, Q. Gan, Threedimensional kernel-based coda attenuation imaging of caldera structures controlling the 1982-84 Campi Flegrei unrest, J. Volcanol. Geotherm. Res. 381, 273-283 (2019).

12. J. Taron, D. Elsworth, K.-B. Min, Numerical simulation of thermal-hydrologic-mechanicalchemical processes in deformable, fractured porous media, Int. J. Rock Mech. Min. Sci. 46, 842-854 (2009).

13. AGIP, "Modello geotermico del sistema flegreo". Servizi Centrali per l'Esplorazione, SERG-MESG; San Donato, (23 pp. (in Italian)), Agip Oil Company (1987).

14. P.P.G. Bruno, S. Maraio, G. Festa, The shallow structure of Solfatara Volcano, Italy, revealed by dense, wide-aperture seismic profiling, Scientific Reports 7, 17386 (2017).

15. S. Vitale, R. Isaia, Fractures and faults in volcanic rocks (Campi Flegrei, southern Italy): Insight into volcano-tectonic processes, International Journal of Earth Sciences 103, 801-819 (2014).

16. F. Cappa, J. Rutqvist, Modeling of coupled deformation and permeability evolution during fault reactivation induced by deep underground injection of $\mathrm{CO}_{2}$, International Journal of Greenhouse Gas Control 5, 336-346 (2011).

17. Q. Gan, D. Elsworth, Analysis of fluid injectioninduced fault reactivation and seismic slip in 
geothermal reservoirs, J. Geophys. Research: Solid Earth 119, 3340-3353 (2014).

18. G. Mandl, "Faulting in brittle rock: An Introduction to the Mechanics of Tectonic Faults", SpringerVerlag Berlin Heidelberg, 444p (2000).

19. S.E. Ingebritsen, C.E. Manning, Permeability of the continental crust: dynamic variations inferred from seismicity and metamorphism, Geofluids 10, 193205 (2010).

20. B.B.T. Wassing, J.D. van Wees, P.A. Fokker, Coupled continuum modeling of fracture reactivation and induced seismicity during enhanced geothermal operations, Geothermics 52, 153-164 (2014).

21. F. Bianco, E. Del Pezzo, G. Saccorotti, G. Ventura, The role of hydrothermal fluids in triggering the July-August 2000 seismic swarm at Campi Flegrei, Italy: Evidence from seismological and mesostructural data, J. Volcanol. Geotherm. Res. 133, 229-246 (2004).

22. A.P. Villaseñor, "Physical and Mechanical Characterization of Altered Volcanic Rocks for the Stability of Volcanic Edifices", $\mathrm{PhD}$ Thesis at Università degli Studi di Milano-Bicocca (2010).

23. J. Rutqvist, C.F. Tsang, Coupled hydromechanical effects of $\mathrm{CO}_{2}$ injection, Developments in Water Science 52, 649-679 (2005).

24. M.J. Heap, P. Baud, P.G. Meredith, S. Vinciguerra, T. Reuschlé, The permeability and elastic moduli of tuff from Campi Flegrei, Italy: implications for ground deformation modelling, Solid Earth 5, 25-44 (2014).

25. S. Aversa, A. Evangelista, Thermal Expansion of Neapolitan Yellow Tuff, Rock Mech. Rock Engng. 26(4), 281-306 (1993).

26. J.H. Dieterich, Modeling of Rock Friction 1. Experimental Results and Constitutive Equations, J. Geophys. Res. 84, 2161-2168 (1979).

27. K. Terzaghi, "Die Berechnung der Durchlässigkeitziffer des Tonesaus dem Verlauf der hydrodynamischen Spannungserscheinungen", Akad. Der Wissenschaften in Wien, Sitzungsberichte, Mathematischnaturwissenschafttliche Klasse. Part IIa, 142 (3/4), 125-138 (1923).

28. J.C. Jaeger, N.G.W. Cook, "Fundamental of Rock Mechanics", Chapman \& Hall, London (1979).

29. S. Baisch, R. Vörös, E. Rothert, H. Stang, R. Jung, R. Schellschmidt, A numerical model for fluid injection induced seismicity at Soultz-sous-Forêts, Int. J. Rock Mech. Min. Sci. 47， 405 (2010).

30. W.L. Ellsworth, Injection-induced earthquakes, Science 341 (2013).

31. Battaglia, C. Troise, F. Obrizzo, F. Pingue, G. De Natale, Evidence for fluid migration as the source of deformation at Campi Flegrei caldera (Italy), Geophy. Research Letters 33 (1), 1-4 (2006).
32. T. Volti, S. Crampin, D.A. Nieuwland, A four-year study of shear-wave splitting in Iceland: 2 . Temporal changes before earthquakes and volcanic eruptions, New Insights into Structural Interpretation and Modelling, Geol. Soc. Lond., Spec. Publ. 12, 135-149 (2003).

33. X. Zhou, T.J. Burbey, E. Westman, The effect of caprock permeability on shear stress path at the aquifer-caprock interface during fluid injection, Intl. Rock Mech. and Min. Sci. 7, 1-10 (2015).

34. H. Kanamori, E.E. Brodsky, The Physics of Earthquakes, American Institute of Physics (Physics Today), 30-40 (2001). 